[Agr. Biol. Chem., Vol. 29, No. 5, p. 407 411, 1965]

\title{
Syntheses of Several Compounds Related to Helminthosporol and their Plant-growth Regulating Activities
}

\author{
By Akira SAkurai and Saburo Tamura \\ Department of Agricultural Chemistry, The University of Tokyo, Tokyo \\ Received November 17, 1964
}

\begin{abstract}
Several compounds related to helminthosporol (I), a natural plant-growth promoter, were prepared from I and their plant-growth regulating activities were examined together with those of the derivatives reported in the previous paper, 1) using rice and lettuce seedlings. Among the compounds tested, helminthosporic acid (III) exhibited marked elongation effect to the shoot growth of rice and lettuce seedlings, whereas the effect of I was specific to the former. Results of the biological test are reported in details.
\end{abstract}

In the previous papers, ${ }^{11}$ the isolation of helminthosporol (I), a natural plant-growth promoter, and its chemical structure were reported. Through the study of Kato et al. ${ }^{2}$ it has been revealed that this compound has a marked elongation effect to the shoot growth of normal and dwarf rice seedlings. On the other hand, helminthosporal (II), which was isolated by de Mayo et al. ${ }^{3)}$ as a toxic substance to wheat, hardly showed such elongation activity. ${ }^{4)}$ To obtain further knowledge on the structure-activity relationship, the authors prepared the following compounds and examined their biological activities. The preparation of compounds II-VII from I has

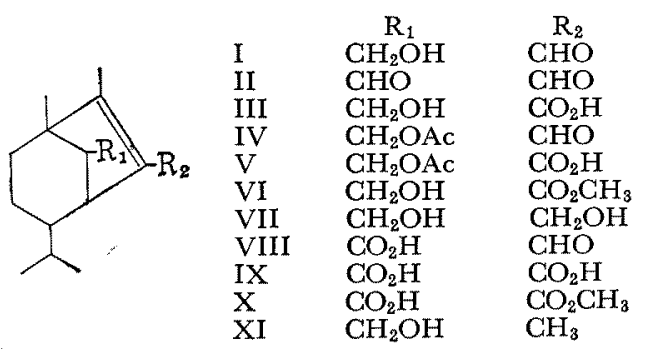

1) S. Tamura, A. Sakurai, K. Kainuma and M. Takai, This Journal, 27, 738 (1963); 29, 216 (1965).

2) J. Kato, Y. Shiotani, S. Tamura and A. Sakurai Naturwiss., 51, 341 (1964)

3) P. de Mayo, E.Y. Spencer and R.W. White, Can. J. Chem., 39, 1608 (1961); ibid., 41, 2996 (1963); J. Am. Chem. Soc., 84, 494 (1962)

4) S. Tamura and A. Sakurai, This Journal, 28, 337 (1963). already been reported in the previous papers. ${ }^{\mathrm{I}}$ In the present paper, syntheses of compounds VIII-XI and results of biological tests with compounds I-XI are described in details.

Oxidation of I with chromium trioxidesulfuric acid in acetone ${ }^{5)}$ gave a mixture of two acidic compounds, which were separated from each other by preparative paper chromatography. One (VIII) of the acids has the molecular formula $\mathrm{C}_{15} \mathrm{H}_{22} \mathrm{O}_{3}$ and shows infrared bands at 1690,1650 and $1620 \mathrm{~cm}^{-1}$ It exhibits an ultraviolet absorption band at $267 \mathrm{~m} \mu$ and gives brown-red color with Brady's reagent indicating that the hydroxyl group in I was oxidized to carboxyl while the $\alpha, \beta$ unsaturated aldehyde group unaffected. Thus this acid was considered to be the aldehyde acid, which had been obtained from II by de Mayo et al.," though direct identification was not undertaken. Another acid (IX), which was also obtained by oxidation of III with the same reagent, has the molecular formula $\mathrm{C}_{15} \mathrm{H}_{22} \mathrm{O}_{4}$ and shows infrared bands at 1690 (broad) and $1623 \mathrm{~cm}^{-1}$ and an ultraviolet band at $246 \mathrm{~m} \mu$. IX corresponds to a diacid, because treatment of this compound with ethereal diazomethane gave a dimethyl ester show-

5) R. G. Curtis, I. Heilbron, E. R.H. Jones and G. F. Wood, J. Chem. Soc., 1953, 457. 
ing infrared bands at 1727 and $1710 \mathrm{~cm}^{-1}$ On the other hand, oxidation of VI with the same reagent gave an ester acid (X), treatment of which with diazomethane gave the same dimethyl ester just described above.

Reduction of the aldehyde group in I to methyl was undertaken by the following way. I was treated with 1,2-ethanedithiol in boron trifluoride etherate to give the thioketal, which was desulfurized with Raney-Ni without isolation. The formation of the expected monool (XI) was confirmed by its NMR spectrum which shows two singlet bands at $\tau 8.54$ and 8.32 attributable to two methyl groups attached to the double bond.

Plant-growth regulating activities of these compounds on rice seedlings were examined at first according to the method of Murakami ${ }^{6}$ with slight modifications. As illustrated in Fig. 1, both helminthosporol (I) and helminthosporic acid (III) exhibited marked elongation effects to the shoot growth almost by the same degree, but helminthosporal (II) showed only slight activity. Remarkable effects of IV and $V$ shown in Fig. 2 indicate that the acetylation of hydroxyl groups in I and III never decreased the activities of the original compounds. Contrary to this facts, VI, methyl ester of III, did not show such effect. VII and IX showed slight elongation effects at higher concentrations but VIII, IX and X did not. For all the compounds tested inhibi-

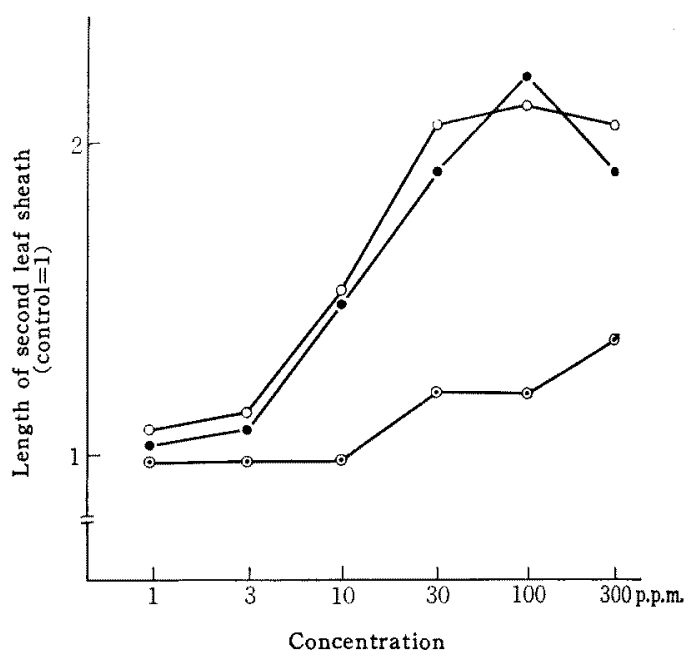

FIG. 1. The Effect of Helminthosporol, Helminthosporal and Helminthosporic Acid on Rice Seedlings.

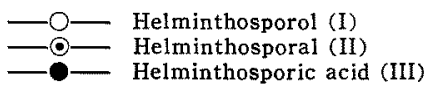

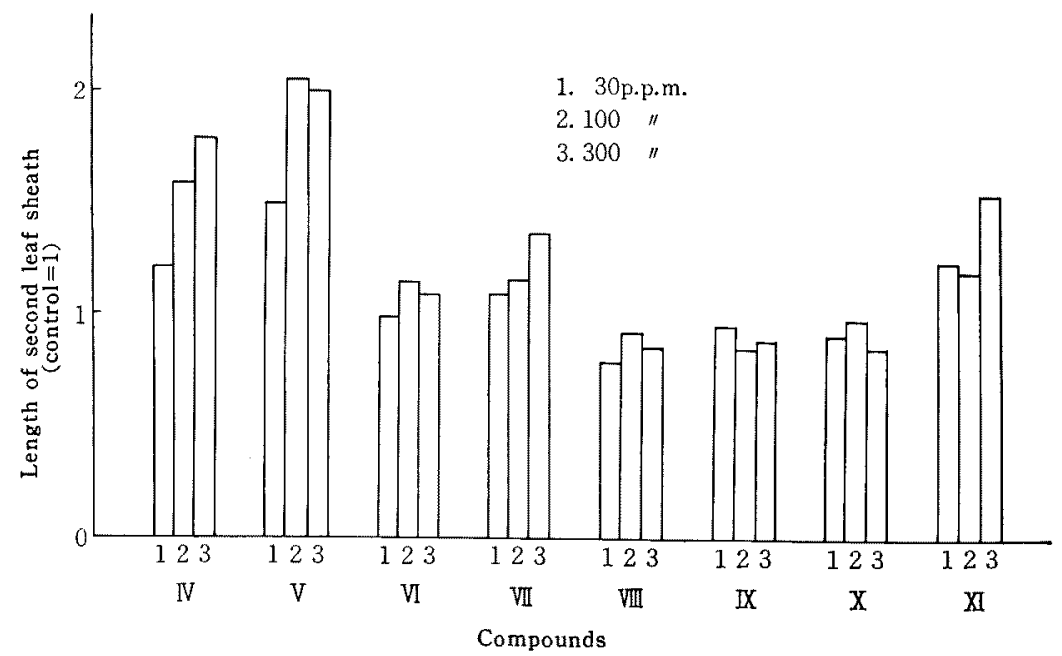

FIG. 2. The Effect of the Compounds Related to Helminthosporol on Rice Seedlings.

6) Y. Murakami, Bot. Mag. Tokyo, 72, 36 (1959). 
tion of the root growth was observed almost to the same extent above the concentration of 100 p.p.m. and the emergence of root was almost completely suppressed at 300 p.p.m.

Subsequently the effect on the growth of lettuce seedlings was compared according to the method of Frankland and Wareing." As shown in Fig. 3, III unexpectedly exhibited a remarkable elongation effect to the growth of hypocotyls, while I showed slight effect. Except IV and V, only VII had slight elongation activity to the hypocotyls among the compounds shown in Fig. 4. On the root growth, I, II and III showed marked stimulation and aside from these three, elongation effect was observed for IV, $\mathrm{V}$ and VIII.

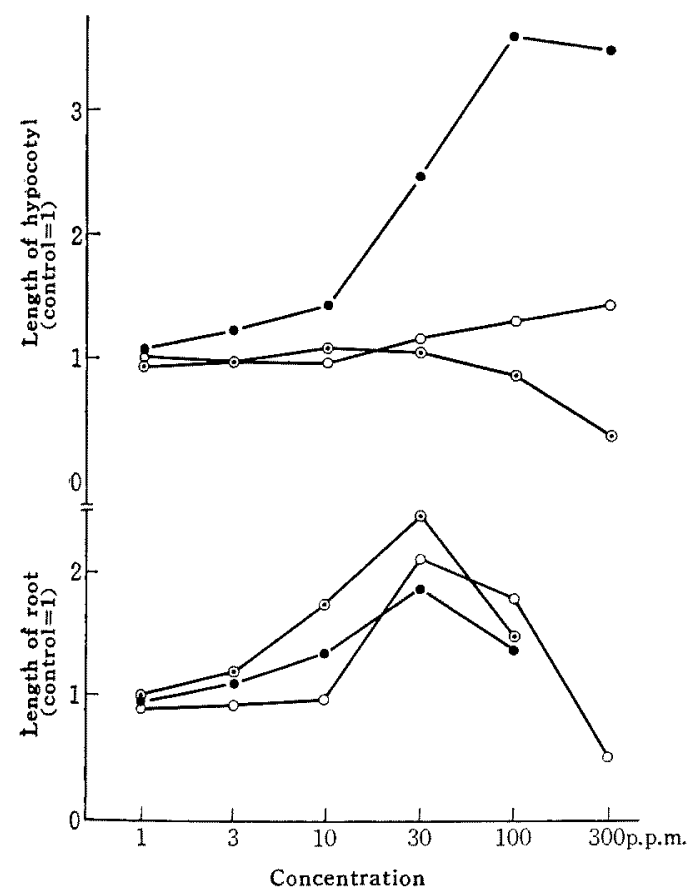

FiG. 3. The Effect of Helminthosporol, Helminthosporal and Helminthosporic Acid on Lettuce Seedlings.

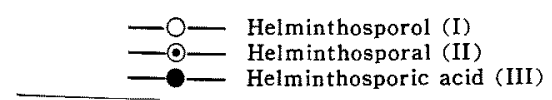

7) B. Frankland and P.F. Wareing, Nature, 185, 255 (1960).
From these experiments, no general trend concerning structure-activity relationship was obtained for helminthosporol and its related compounds. However, it is noteworthy that helminthosporic acid was effective to the shoot growth of both rice and lettuce seedlings, whereas helminthosporol was only effective to the former.

\section{EXPERIMENTAL}

Infrared spectra were measured with Koken DS-301 and JASCO IR-S KCl spectrophotometers and ultraviolet spectra with Cary 14-PM spectrophotometer. NMR measurements were made with Varian A-60 spectrometer in around $10 \%(\mathrm{v} / \mathrm{w})$ carbon tetrachloride solutions. Melting points were uncorrected.

\section{Chromium Trioxide Oxidation of Helmintho- sporol}

Chromium trioxide in sulfuric acid solution (Jones' reagent $\left.{ }^{5}\right)$ was added dropwise to a solution of $530 \mathrm{mg}$ of $\mathrm{I}$ in $5 \mathrm{ml}$ of acetone at $15 \sim 20^{\circ} \mathrm{C}$ with stirring. Until rapid consumption of the oxidant ceased, $0.96 \mathrm{ml}$ of the reagent was required. Then the oxidation product was extracted with ether, and an oily mixture of acidic products $(440 \mathrm{mg}$ ) was obtained after evaporation of the solvent. This was applied to paper chromatography using six sheets of $40 \times 40 \mathrm{~cm}$ filter paper and developed with the solvent system of $n$-butanol$1.5 \mathrm{~N}$ ammonia $(3: 1, \mathrm{v} / \mathrm{v})$. The zone of $R_{F} 0.6 \sim 0.8$, positive for Brady's reagent, was eluted with methanol which was evaporated to give a solid. This was further purified by a silicic acid column using benzene$5 \%$ ethyl acetate as eluent, and then recrystallized from $n$-hexane to give VIII (100 mg). M.p. 128 $130^{\circ} \mathrm{C}$. $\nu_{\max }^{\text {Nujol }} 1690,1650$ and $1620 \mathrm{~cm}^{-1} .2 \max 267 \mathrm{~m} \mu$ ( $\varepsilon 8000$ in $95 \%$ ethanol). Anal. Found: C, 71.76; H, 8.76. Calcd. for $\mathrm{C}_{15} \mathrm{H}_{22} \mathrm{O}_{3}: \mathrm{C}, 71.97 ; \mathrm{H}, 8.86 \%$. Reported physical data ${ }^{3}$ : m.p. $127 \sim 128^{\circ} \mathrm{C}_{\text {; }} \nu_{\max }^{\mathrm{CCl}_{4}} 1705$, $1670 \mathrm{~cm}^{-1} ; \lambda_{\max } 265 \mathrm{~m} \mu$ ( $\varepsilon 7000$ in ethanol). Another zone of $R_{F} \quad 0.3 \sim 0.5$ was eluted with methanol. Evaporation of the solvent gave crystals of IX, which was recrystallized from ethyl acetate- $n$-hexane. M.p. $210 \sim 214^{\circ} \mathrm{C}$. $\begin{gathered}\text { Nujol } \\ \text { max }\end{gathered} 1690$ and $1623 \mathrm{~cm}^{-1}$. $\lambda \max 246 \mathrm{~m} \mu$ ( $\varepsilon 6000$ in $95 \%$ ethanol). Anal. Found: C, 67.34; $\mathrm{H}$, 8.47. Calcd. for $\mathrm{C}_{15} \mathrm{H}_{22} \mathrm{O}_{4}: \mathrm{C}, 67.64 ; \mathrm{H}, 8.33 \%$. It gave an oily dimethyl ester by treatment with ethereal diazomethane. $\nu_{\max } 1727,1710$ and $1634 \mathrm{~cm}^{-1}$. Anal. Found: $\mathrm{C}, 69.47 ; \mathrm{H}, 8.90$. Calcd. for $\mathrm{C}_{17} \mathrm{H}_{26} \mathrm{O}_{4}: \mathrm{C}$, $69.36 ; \mathrm{H}, 8.90 \%$. 

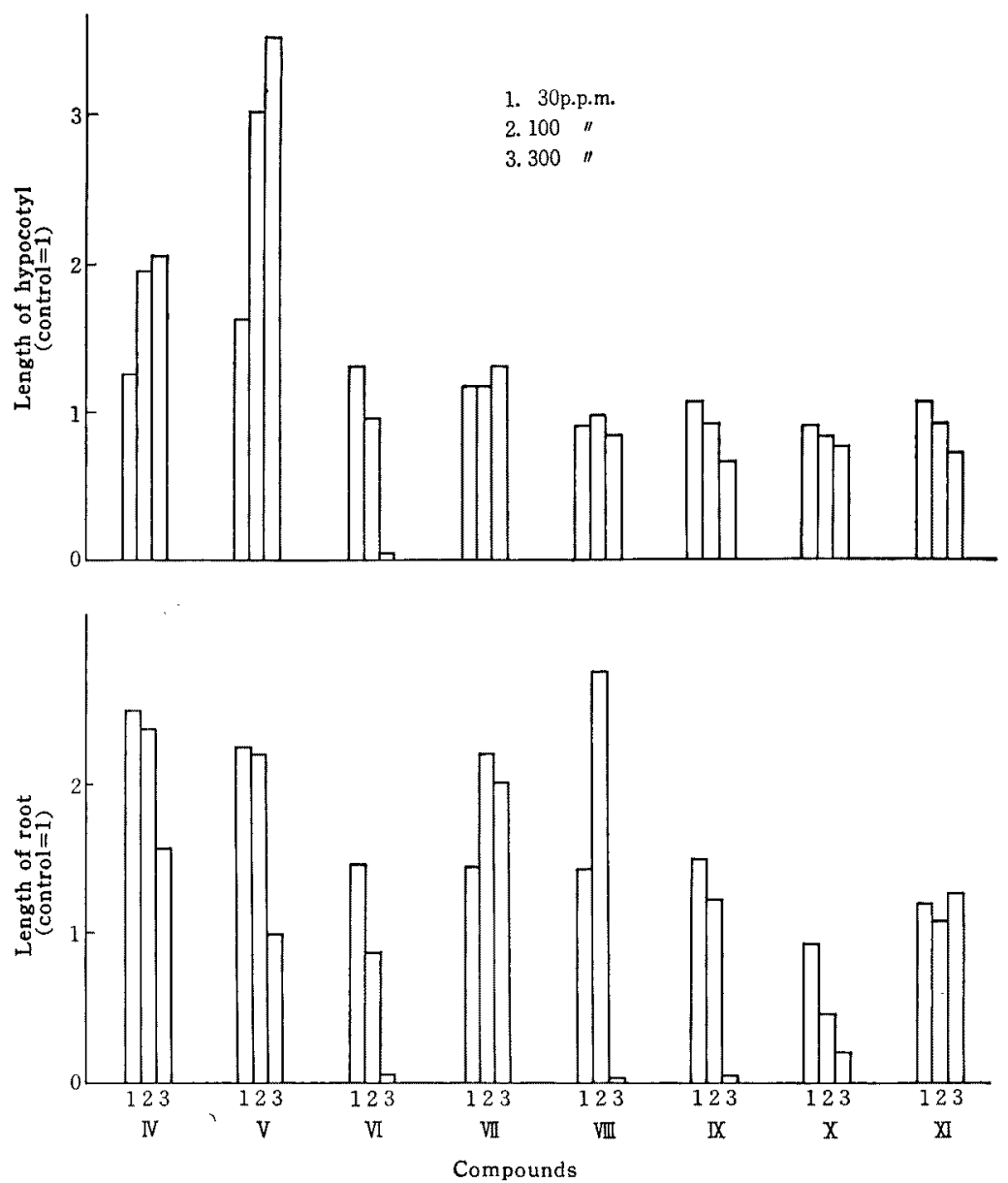

FIG. 4. The Effect of the Compounds Related to Helminthosporol on Lettuce Seedlings.

Chromium Trioxide Oxidation of Helminthosporic Acid and its Methyl Ester

A solution of $130 \mathrm{mg}$ of III in $3 \mathrm{ml}$. of acetone was treated with Jones' reagent in the same way as described above, $0.25 \mathrm{ml}$ of the reagent was needed for the completion of oxidation. The reaction mixture was extracted with ether. The solid, obtained after evaporation of the solvent, was recrystallized from ethyl acetate $n$-hexane to give IX $(100 \mathrm{mg})$. M.p. and mixed m.p. $208 \sim 210^{\circ} \mathrm{C}$. Its infrared spectrum was identical in every respects with that obtained from $\mathrm{I}$. VI (140 mg) was oxidized in the same manner to give $\mathrm{X}$ (106 mg), which was recrystallized from $n$ hexane. M.p. $91 \sim 93^{\circ} \mathrm{C}$. $\underset{\nu_{\max }^{N u j o l}}{\stackrel{N}{N_{u}}} 1700,1670$ and
$1630 \mathrm{~cm}^{-1}$. Treatment of $\mathrm{X}$ with ethereal diazomethane gave an oily dimethyl ester, which was identified with that derived from IX by comparison of their infrared spectra and by thin layer chromatography.

\section{Reduction of Helminthosporol}

I $(500 \mathrm{mg}$ ) was treated with $0.5 \mathrm{ml}$ of 1 ,2-ethanedithiol in the presence of $0.5 \mathrm{ml}$ of boron trifluoride etherate and let to stand at room temperature overnight. Water was added to the reaction mixture, which was extracted with ether. The ether solution was washed with dil. alkali and dried over anhydrous sodium sulfate, Evaporation of the ether gave an oily product, which was desulfurized in the following way without further purification and characterization. 
The oil was dissolved in ethanol, and to this solution Raney-Ni (W-6) prepared from $12.5 \mathrm{~g}$ of Ni-alloy was added; and the mixture refluxed for $8 \mathrm{hrs.} \mathrm{After}$ filtration of the catalyst, the ethanol was evaporated and the residue extracted with ether. Evaporation of the ether gave an oily product which was chromatographed on silicic acid column ( $7 \mathrm{~g}$ ) and eluted with benzene to give $210 \mathrm{mg}$ of colorless oil (XI). $\nu \max$ 3350 (alcohol) and 1645 (double bond) $\mathrm{cm}^{-1}$. Anal. Found: $\mathrm{C}, 80.85 ; \mathrm{H}, 11.69$. Calcd. for $\mathrm{C}_{15} \mathrm{H}_{26} \mathrm{O}: \mathrm{C}$, $81.02 ; \mathrm{H}, 11.79 \%$.

\section{Bioassay}

a) Rice Seedlings. Definite amounts of methanol solutions containing the test compound at various concentrations were poured onto absorbent cotton placed in Petri dishes, $5 \mathrm{~cm}$ in diameter, to obtain serial contents of $0.01,0.03,0.1,0.3,1.0$ and $3.0 \mathrm{mg}$ of the compound in each dish. The solvent was evaporated by standing the dishes in the air. For such compounds as I, II, IV and VIII which are unstable to air oxidation, the solvent was driven off in a stream of nitrogen gas. Then $10 \mathrm{ml}$ of distilled water was poured into each dish, and test solutions of $1,3,10,30,100$ and 300 p.p.m. were obtained. In each dish were placed twelve rice seeds (Oryzae sativa L. cv. Norin No. 29) which had been germinated in distilled water by keeping in darkeness at $30^{\circ} \mathrm{C}$ for 3 days. Then the dishes were incubated at $25^{\circ} \mathrm{C}$ under white fluorescent tubes of about $2000 \mathrm{Lux}$. After 9 days incubation the length of the second leaf sheath was measured. At the end of this period, the average sheath length of seedlings grown in distilled water as the control became $26 \sim 30 \mathrm{~mm}$.

b) Lettuce Seedlings. The methanol solutions of the test compound were poured onto two sheets of filter paper placed in Petri dishes, $5 \mathrm{~cm}$ in diameter, to obtain serial contents of $0.003,0.009,0.03,0.09$, 0.3 and $0.9 \mathrm{mg}$ of the compound in each dish. After evaporation of the solvent in the same way as described above, $3 \mathrm{ml}$ of Hoagland's solution was poured into each dish, and test solutions of $1,3,10$, 30,100 and 300 p.p.m. were obtained. In the dishes thus prepared were placed twelve each of lettuce seeds (Lactuca sativa L. cv. Wirehead) which had been germinated in distilled water by keeping at $25^{\circ} \mathrm{C}$ for $24 \mathrm{hrs}$. Then the dishes were incubated for 3 days at $25^{\circ} \mathrm{C}$ under white fluorescent tubes of about $2000 \mathrm{Lux}$. The length of both hypocotyl and root was measured. In this period of incubation, the average length of hypocotyl and root of the control plants became $2.0 \sim 2.5$ and $13 \sim 17 \mathrm{~mm}$ respectively.

Acknowledgement. The authors wish to thank Dr. T. Hashimoto for his helpfull advice on biological tests and Miss H. Imai of this laboratory for her technical assistance. They are also indebted to the members of Microanalysis Laboratories of Institute of Applied Microbiology and Department of Agricultural Chemistry, the University of Tokyo for microanalyses. Thanks are also due to Sankyo Co. for NMR measurements and to $\mathrm{Mr}$. K. Aizawa for infrared and ultraviolet analyses. The preparation of crude samples of helminthosporol by fermentation are indebted to Sankyo Co. 